\title{
BMJ Open Are you really doing 'codesign'? Critical reflections when working with vulnerable populations
}

\author{
Sandra Moll (D) , ${ }^{1}$ Michelle Wyndham-West, ${ }^{2}$ Gillian Mulvale, ${ }^{3}$ Sean Park, ${ }^{4}$ \\ Alexis Buettgen, ${ }^{1,5}$ Michelle Phoenix, ${ }^{6}$ Robert Fleisig, ${ }^{7}$ Emma Bruce ${ }^{1}$
}

To cite: Moll S, WyndhamWest M, Mulvale G, et al. Are you really doing 'codesign'? Critical reflections when working with vulnerable populations. BMJ Open 2020;10:e038339. doi:10.1136/ bmjopen-2020-038339

- Prepublication history for this paper is available online. To view these files, please visit the journal online (http://dx.doi. org/10.1136/bmjopen-2020038339).

Received 06 March 2020 Revised 04 October 2020 Accepted 12 October 2020

Check for updates

(c) Author(s) (or their employer(s)) 2020. Re-use permitted under CC BY-NC. No commercial re-use. See rights and permissions. Published by BMJ.

For numbered affiliations see end of article.

Correspondence to

Dr Sandra Moll;

molls@mcmaster.ca

\section{ABSTRACT}

'Codesign' and associated terms such as 'coproduction' or 'patient engagement', are increasingly common in the health research literature, due to an increased emphasis on the importance of ensuring that research related to service/systems development is meaningful to endusers. However, there continues to be a lack of clarity regarding the key principles and practices of codesign, and wide variation in the extent to which service users are meaningfully engaged in the process. These issues are particularly acute when end-users include populations who have significant health and healthcare disparities that are linked to a range of intersecting vulnerabilities (eg, poverty, language barriers, age, disability, minority status, stigmatised conditions). The purpose of this paper is to prompt critical reflection on the nature of codesign research with vulnerable populations, including key issues to consider in the initial planning phases, the implementation process, and final outputs. Risks and tensions will be identified in each phase of the process, followed by a tool to foster reflexivity in codesign processes to address these issues.

\section{INTRODUCTION}

Over the last decade, codesign has emerged as a ubiquitous research and service/systems development approach across a myriad of health-oriented disciplines including, but not limited to, health services, ${ }^{1-4}$ quality improvement ${ }^{5}$ health technology development ${ }^{6}{ }^{7}$; Indigenous health ${ }^{89}$ and community-based health. ${ }^{10}$ Application of codesign approaches are increasingly evident with populations who experience vulnerability due to social, economic and environmental barriers, from children, ${ }^{6} 1112$ through to older adults. ${ }^{13-15}$ Researchers and practitioners within these disciplines have deployed codesign approaches across a range of settings, using various terms such as cocreation, coproduction, coresearch, experience-based codesign, human-centred design, technology codesign, participatory research, collaborative and community-based research. ${ }^{16} 17$ The terms are linked to sets of core principles regarding the value of lived experience, collaboration, building on capabilities and creativity. ${ }^{16}$ Codesign, at a basic level, refers to application of user-centric research and service/ systems development approaches in order to solve a particular problem or challenge. ${ }^{18}$ However, codesign has also been described as a dynamic, creative approach to research that embraces partnership with community, and focuses on systems change and improving human experience. ${ }^{16}$

The increasing use of the term codesign and its associated methodologies has made it challenging to distinguish whether or not the term has been co-opted in such a way that sidesteps meaningful engagement with the original principles of codesign: distribution of power in research, amelioration of the human experience and positive societal impact. These issues are particularly acute when engaging populations who are 'vulnerable'; considering vulnerability not as an individual characteristic, but as the result of social and systemic barriers (eg, poverty, literacy, language barriers, and discrimination related to age, disability status, ethnicity/ race, gender).

In this article, we critically discuss three questions, with a particular focus on research with vulnerable service users: (1) what is the epistemological starting point that is underpinning the decision to apply codesign processes and techniques?; (2) how are codesign methodologies, planned, applied and adapted while engaging in iterative 'research through design' processes?; (3) what type of post codesign outputs can be anticipated and created, and what will the manifest and latent impacts of these outputs be? These questions are based on synthesis of theoretical and practical writings about codesign from a range of disciplines, including engineering, business, health sciences, rehabilitation and social sciences, as well as our own experiences as codesign researchers in these 
disciplines. Our standpoint as researchers is informed by reflections on our varied experiences in codesign with a range of communities, including families of children with disabilities, youth with mental health issues, newcomers, and older adults who are precariously housed. The critical discussion which ensues places a particular emphasis on how power is conceptualised, deployed and received ${ }^{19}$ within codesign processes aimed to ameliorate health services, products and experiences for vulnerable individuals and groups.

\section{WHERE ARE YOU STARTING FROM?}

Advancing effective and ethical codesign should start with critical reflection on the epistemological beliefs that are driving initiation of the process, including the 'mindset' of the codesign facilitators. Codesign should begin with critical and embodied reflexivity that attends to (1) ourselves-the subjective self or 'I'; (2) our relationship with others-the intersubjective 'we'; and (3) the systems in which we and others are embedded-the objective 'it'. ${ }^{20}$

The first point of reflection is internal; as a facilitator of codesign, it is important to consider the worldview, assumptions and values that you bring to the process. Codesign facilitators need to embrace critical, reflexive practice, including development of a subjective, embodied understanding of their own standpoints and epistemological frameworks that will impact their relationships with others. ${ }^{21}$ They need to be capable of improvising and taking other perspectives, and be willing to be transformed in the process. ${ }^{22}$ These capabilities are cultivated through enhancing mindful awareness of, and working with the thoughts, emotions, perceptions, sensations, that arise as part of being in an interpersonal relationship. ${ }^{23}$

The second point of reflection is on your relationship with others who are engaged in the codesign. This includes attending to the effects that you have as a researcher, educator and/or practitioner at every step of the design process. It also involves a commitment to ongoing dialogue about various ways of knowing, the interrogation of power and privilege, and making the time and space to listen, share and cocreate. ${ }^{24}$ The humanity and multidimensionality of all participants must be respected and attended to with care, compassion, creativity and humility. Relationships require openness and vulnerability in the immediacy of human-to-human connection. ${ }^{25}$

The third and final point of reflection is on the system in which the codesign process will occur. There may be a clash of values since many organisations operate within a sociopolitical environment that privileges individualism over collectivism, self-sufficiency over collaboration, and scientific expertise over other ways of knowing based on lived experiences. ${ }^{326}$ The fundamental principles of collaboration in codesign may be subverted in the drive for efficiency and top-down decision making. Critical awareness and resistance to these pressures may be needed in order to find the time and space required for an authentic way of working together for social justice and change. Beginning a codesign project requires institutional support to ensure that there is a commitment to critical thinking, learning and change, ${ }^{27}$ that diverse people are given an opportunity to participate ${ }^{28}$ and that sufficient resources (including funding and space) are provided.

\section{WHAT SHOULD YOU BE DOING?}

Codesign has been described as both a philosophy and a method ${ }^{27}$ that includes authentic and equitable collaboration between stakeholders in projects that are emergent, flexible and iterative. ${ }^{28}$ There are several specific approaches that have been used in the context of healthcare, including experience-based codesign (EBCD), ${ }^{29} 30$ participatory research ${ }^{18}$ and user centred design. ${ }^{31}$ Each approach has its own processes and tools, but there are several overarching issues to consider in optimising the process of collaboration and design.

First, it is critical to include diverse people in the codesign process, including those with lived experience, those who deliver or implement a service or programme, and other key stakeholders or influencers. ${ }^{28}$ A noteworthy criticism of codesign specifically, and patient-oriented research generally, is that vulnerable populations may be excluded $^{32}$ or represented by 'super users' who do not reflect the typical population. ${ }^{33}$ Super users are individuals who frequently contribute to research projects. They are often invited to participate since they are actively engaged, articulate and clearly understand their role in the process. One of the dangers, however, is that over time, socialisation to their research role may desensitise them to the perspective of those experiencing greater disenfranchisement. ${ }^{33}$ It takes time and effort to ensure representation from the important, but often unheard voices of communities who face many barriers to engagement.

When engaging groups from historically marginalised communities, sensitivity to power differentials and creative approaches may be needed to ensure a safe and inclusive space for collaboration. Invited spaces have been criticised for perpetuating marginalisation and tokenism, since unexamined power imbalances may delegitimise forms of knowledge that depart from the status quo. ${ }^{34}$ Principles and tools for engagement could include: (1) formalising agreements for shared leadership, decision making and ownership of knowledge; (2) providing training and ongoing mentorship for new participants who may be uncomfortable and/or unfamiliar with the process; (3) ensuring flexibility to account for differences and fluctuations in ability to participate; and (4) establishing formal recognition for the value of service user input. ${ }^{28} 33$ Richards and colleagues ${ }^{35}$ present an insightful argument regarding compensation for service users in order to recognise vulnerability, promote equity, facilitate commitment and remove barriers to participation. They suggest starting the conversation early to build 
relationships, negotiating a fair rate that addresses the needs of all parties, and establishing a formal agreement on roles and responsibilities in order to avoid the risk of tokenism.

Specific steps of codesign may vary depending on the project, however, core processes include building trust, finding voice, sharing perspectives and creating a common vision for change. ${ }^{28}$ Arts-based tools and techniques can be incorporated to generate initial insights into stakeholder experiences, as well to foster creativity in designing solutions. Generative design strategies, as outlined by Sanders and Stappers, ${ }^{31}$ emphasise the role of 'doing' and 'making' as alternate paths of expression that can evoke deeper insights and creative solutions. They highlight how a range of probes, generative toolkits and prototyping strategies can facilitate the codesign process, using creative tools such as video, storyboards, clay and even Lego to evoke insights and ideas that transcend what people might put into words. These strategies may be particularly effective to engage service users who may have difficulty with purely verbal interviews or focus group discussions (eg, recent immigrants, young children, older adults with dementia).

Rather than following a series of rigid steps, working with vulnerable populations requires following a set of core principles; 'taking time to fully engage, listen for understanding and not move forward until participants or communities are ready' (p295). ${ }^{28}$ One of the challenges for codesign facilitators is responding to pressures related to resource and time constraints that could compromise the process. $^{27}$

\section{WHAT ARE YOUR INTENDED OUTPUTS?}

In addition to how codesign is implemented, it is critical to examine outputs of the process. With its roots in design thinking and action research, codesign involves creating prototype solutions to address the priority problems or issues. Ultimately, the process should continue to implementation and evaluation of the proposed solutions, with a commitment to ongoing collaboration in the process of change. ${ }^{36}{ }^{37}$ Without this movement to positive change, participants can become disempowered and even resentful, particularly with perpetuation of the status quo.

The specific outputs and outcomes of codesign are varied, but can occur on several levels, from individual to systems change. A survey of $59 \mathrm{EBCD}$ projects in six countries found that most projects initially targeted small quality improvements, however the legacies of the codesign work had much larger impacts in terms of 'deep changes in attitudes and behaviours' ${ }^{30}$ Similarly, Palmer et $a l^{88}$ argue that while practical solutions are important, the skills gained by service users, family/caregivers and staff in negotiating new ways of advancing the future that they have helped to shape is even more significant. This can be particularly important for groups who have a history of fractured relations (eg, mental health service users), wherein new shared identities can be developed as the basis for a restructuring of future relationships. ${ }^{39} 40$ These attitudinal and behavioural shifts are important in shifting culture within a service, and thereby improve the inter-personal dynamics of care, ${ }^{41}$ including power sharing and enhanced communication between service professionals and users. ${ }^{42}$ The ultimate hope is for positive, sustained change in health and/or social services through outputs of greater empathy, increased trust, shared commitment and advocacy. ${ }^{38}$ The extent to which this occurs will depend on adopting and adhering to core principles and skilled facilitation..$^{28} 43$

\section{THE WAY FORWARD}

The ubiquity of codesign as a strategy for health service and system reform, and the diversity in how it is defined, begs the question of whether there should be standards for implementation and evaluation, as well as critical reflection on the implications of doing this work with participants who experience a range of vulnerabilities.

As noted earlier, careful planning and critical reflection is needed to ensure that the process does not produce 'token' service user involvement or further perpetuate inequities. A useful guidance document developed by INVOLVE $^{44}$ outlines key principles and strategies to consider in coproducing a research project. Also, guidelines for reporting on patient and public involvement in health and social care research (GRIPP2) have been proposed as a strategy to advance quality and transparency in codesign. ${ }^{45}$ These guidelines are a helpful step toward consistency in language and reporting of codesign processes, outputs and outcomes, as well as a useful tool for generating critical reflection on the engagement of service users in research. The next steps are to create more specific questions to critically evaluate codesign projects stemming from the three overarching questions addressed in this article. Box 1 outlines a list of suggested sub-questions to consider, which reflect the high level of engagement expected throughout the entirety of a codesign project. It should be noted that these questions are directed towards researchers and facilitators of codesign initiatives, as a tool to prompt reflexive analysis. Stakeholders who represent community partners and end users should also be engaged in dialogue about how to optimise the codesign process.

Another key step forward will be more robust evaluation of codesign work, in terms of costs and benefits, quality improvement and wider systems impacts. ${ }^{30}$ In their review of health-related codesign research, Slatterly and colleagues ${ }^{18}$ echo the call for systematic research on the effectiveness of various codesign approaches and strategies. They emphasise that research should be theoretically informed, and build on implementation science principles that capture the context and complexity of the codesign process. Realist evaluation, therefore, is a promising approach, since it considers the impact of the context, as well as the mechanisms of change that shape project outcomes. ${ }^{46}$ Realist evaluations are also based 
Box 1 A tool to foster reflexivity in codesign with vulnerable populations

Where are you starting from?

1. What are your worldviews, assumptions and values relevant to the issue(s) or problem(s) you are trying to address? How open are you to being transformed by other worldviews?

2. How will you respectfully interact and compassionately attend to human diversity, and various ways of knowing?

3. How will you interrogate power and privilege?

4. How will you make time and space for sharing, dialogue and cocreation despite timelines and resource constraints?

\section{What should you be doing?}

1. How will you purposefully select a broad range of stakeholder perspectives and representatives? How do you define inclusive participation?

2. What tools, processes and techniques will you use to fully understand lived experiences, build rapport and foster trust within an environment of open and respectful dialogue?

3. How will you tap into tacit knowledge, creativity and shared meaning of diverse perspectives to cocreate a shared vision for improvement?

\section{What are your intended outputs?}

1. How will you facilitate implementation of prototype solutions?

2. How will you foster commitment to change to minimise the risk of tokenistic engagement of vulnerable populations and perpetuating the status quo?

3. How will your codesign processes build capacity and forge new ways of communicating, and in doing so shift service cultures toward greater empathy, trust, shared commitment and advocacy?

4. How will you determine if your project has achieved the desired outcomes? Will these outcomes be sustainable?

on a theory of change which can help to explicate the relationship between various dimensions of the codesign process and how they lead to change. ${ }^{47}$

In conclusion, it should be recognised that codesign can be a powerful tool to contest vulnerability through authentic collaboration in research and service/system design. Codesign is a philosophy and method that has the potential to empower people, both researchers and participants, service providers and service users, policy makers and community members. It must be recognised, however, that codesign is ultimately a relational process and as such, careful attention must be paid to ensuring that the process does not perpetuate inequities. The realities of fiscal and time constraints must be balanced with critical reflexivity and commitment to creating meaningful collaborative solutions.

\section{Author affiliations}

${ }^{1}$ School of Rehabilitation Science, McMaster University, Hamilton, Ontario, Canada ${ }^{2}$ Faculty of Design, OCAD University, Toronto, Ontario, Canada

${ }^{3}$ DeGroote School of Business, McMaster University, Hamilton, Ontario, Canada ${ }^{4}$ Department of Medicine, Faculty of Health Sciences, McMaster University, Hamilton, Ontario, Canada

${ }^{5}$ Canadian Centre on Disability Studies, Inc. o/a Eviance, Winnipeg, Manitoba, Canada

${ }^{6}$ School of Rehabilitation Science and CanChild, McMaster University Faculty of Health Sciences, Hamilton, Ontario, Canada
${ }^{7}$ Walter G. Booth School of Engineering Practice and Technology, McMaster University Faculty of Engineering, Hamilton, Ontario, Canada

Twitter Sean Park @profseanpark and Robert Fleisig @RobertFleisig

Contributors The first author (SM) was responsible for the overall paper, incorporating input from the team. MW-W, GM, SP, AB, MP were all involved in writing sections of the paper. All authors (including RF and EB) were involved in the conceptualisation of the paper and provided feedback on draft versions.

Funding The codesign hub for Vulnerable Populations is funded through the McMaster (SAF2019) Strategic Alignment Initiative.

Competing interests None declared.

Patient consent for publication Not required.

Provenance and peer review Not commissioned; externally peer reviewed.

Open access This is an open access article distributed in accordance with the Creative Commons Attribution Non Commercial (CC BY-NC 4.0) license, which permits others to distribute, remix, adapt, build upon this work non-commercially, and license their derivative works on different terms, provided the original work is properly cited, appropriate credit is given, any changes made indicated, and the use is non-commercial. See: http://creativecommons.org/licenses/by-nc/4.0/.

\section{ORCID iD}

Sandra Moll http://orcid.org/0000-0002-1937-0103

\section{REFERENCES}

1 Bowen S, McSeveny K, Lockley E, et al. How was it for you? experiences of participatory design in the UK health service. CoDesign 2013;9:230-46.

2 Bowen S, Dearden A, Wright P, et al. Co-designing better outpatient services for older people: inspiration stories for participatory design with health and social care institutions workshop. 11th biennial participatory design. Sydney, Australia, 2010.

3 Mulvale G, Moll S, Miatello A, et al. Codesigning health and other public services with vulnerable and disadvantaged populations: insights from an international collaboration. Health Expect 2019;22:284-97.

4 Wolstenholme Det al. Design-Led service improvement for older people. Australas Med J 2010;3:465-70.

5 Greenhalgh T, Russell J, Swinglehurst D. Narrative methods in quality improvement research. Qual Saf Health Care 2005;14:443-9.

6 Allsop MJ, Holt RJ, Levesley MC, et al. The engagement of children with disabilities in health-related technology design processes: identifying methodology. Disabil Rehabil Assist Technol 2010;5:1-13.

7 Sutcliffe A, Thew S, De Bruijn O, et al. User engagement by usercentred design in e-health. Philos Trans A Math Phys Eng Sci 2010;368:4209-24

8 Blodgett AT, Schinke RJ, Peltier D, et al. May the circle be unbroken: the research recommendations of Aboriginal community members engaged in participatory action research with university academics. $J$ Sport Soc Issues 2011;35:264-83.

9 Moscou K, Rempel K, Beeman C, et al. A healthy neighbourhood: voices of Indigenous youth.Brandon, Manitoba. Canada: Centre for Aboriginal and Rural Education Studies, 2018.

10 Buffel T, Handler S, Philipson C. Age-Friendly cities and communities: AGlobal perspective. Great Britain: Policy Press, 2018.

11 Beresford B. Working on Well-Being: Researchers' Experiences of a Participative Approach to Understanding the Subjective Well-Being of Disabled Young People. Child Soc 2012;26:234-40.

12 Veinot TC, Flicker SE, Skinner HA, et al. "Supposed to make you better but it doesn't really": HIV-positive youths' perceptions of HIV treatment. J Adolesc Health 2006;38:261-7.

13 Holroyd-Leduc J, Resin J, Ashley L, et al. Giving voice to older adults living with frailty and their family caregivers: engagement of older adults living with frailty in research, health care decision making, and in health policy. Res Involv Engagem 2016;2:1-19.

14 Burnell KJ, Selwood A, Sullivan T, et al. Involving service users in the development of the support at home: interventions to enhance life in dementia carer supporter programme for family carers of people with dementia. Health Expect 2015;18:95-110.

15 Tanner D. Co-research with older people with dementia: experience and reflections. J Ment Health 2012;21:296-306.

16 Greenhalgh T, Jackson C, Shaw S, et al. Achieving research impact through co-creation in community-based health services: literature review and case study. Milbank Q 2016;94:392-429. 
17 Littlechild R, Tanner D, Hall K. Co-research with older people: perspectives on impact. Qual Soc Work 2015;14:18-35.

18 Slattery P, Saeri AK, Bragge P. Research co-design in health: a rapid overview of reviews. Health Res Policy Sys 2020;18:1-13.

19 Allen A. The politics of ourselves: power, autonomy and gender in contemporary critical theory. New York: Columbia University Press, 2013.

20 Hochachka G, Sustainability D. Developing the self: an integral approach to international and community development. Victoria, Canada: Trafford, 2009.

21 Cunliffe AL. On becoming a critically reflexive practitioner. J Manag Educ 2004;28:407-26.

22 Keeney H, Keeney B, Chenail R. Recursive frame analysis: a qualitative research method for mapping Change-Oriented discourse. Fort Lauderdale, FL: TQR Books, 2015.

23 Varela F. Ethical know-how: action, wisdom, cognition. Palo Alto, CA: Stanford University Press, 1999.

24 Hankivsky O. Intersectionality 101. Burnaby: Institute for Intersectionality Research and Policy, Simon Fraser University, 2014.

25 Cipolla C. Designing for vulnerability: interpersonal relations and design. She Ji: The Journal of Design, Economics, and Innovation 2018;4:111-22.

26 Kelly K, Caputo T. Community: a contemporary analysis of policies, programs, andPractices. Toronto, Ontario: University of Toronto Press, 2011.

27 Donetto S, Pierri P, Tsianakas V, et al. Experience-Based Co-design and healthcare improvement: Realizing participatory design in the public sector. The Design Journal 2015;18:227-48.

28 Mulvale G, Moll S, Miatello A, et al. Co-designing services for youth with mental health issues: novel elicitation approaches. Int J Qual Methods 2019;18:160940691881624.

29 Bate P, Robert G. Bringing user experience to healthcare improvement: the concepts, methods and practices of experiencebased design. Radcliffe Publishing: Oxford, 2007.

30 Donetto S, Tsianakas V, Robert G, et al. Using experience-based co-design $(E B C D)$ to improve the quality of healthcare: mapping where we are now and establishing future directions. London: King's College London, 2014.

31 Sanders EB-N, Stappers PJ, Probes SP. Probes, toolkits and prototypes: three approaches to making in codesigning. CoDesign 2014;10:5-14.

32 Gonzalez M, Phoenix M, Saxena S, et al. Strategies used to engage hard-to-reach populations in childhood disability research: a scoping review. Disabil Rehabil 2020:1-13.
33 Black A, Strain K, Wallsworth C, et al. What constitutes meaningful engagement for patients and families as partners on research teams? $J$ Health Serv Res Policy 2018;23:158-67.

34 de Freitas C, Martin G. Inclusive public participation in health: policy, practice and theoretical contributions to promote the involvement of marginalised groups in healthcare. Soc Sci Med 2015;135:31-9.

35 Richards DP, Jordan I, Strain K, et al. Patient partner compensation in research and health care: the patient perspective on why and how. Patient Exp J 2018;5:6-12.

36 Bovaird T. Beyond engagement and participation: user and community coproduction of public services. Public Adm Rev 2007:67:846-60.

37 Loeffler E, Bovaird T. User and community co-production of public services: what does the evidence tell us? Int J Public Admin 2016;39:1006-19.

38 Palmer VJ, Weavell W, Callander R, et al. The participatory Zeitgeist: an explanatory theoretical model of change in an era of coproduction and codesign in healthcare improvement. Med Humanit 2019;45:247-57.

39 Mulvale G, Green J, Miatello A, et al. Finding harmony within dissonance: engaging patients, family/caregivers and service providers in research to fundamentally restructure relationships through integrative dynamics. Health Expect 2020. doi:10.1111/ hex.13063. [Epub ahead of print: 11 Jun 2020].

40 Shapiro D. Negotiating the Nonnegotiable: how to resolve your most emotionally charged conflicts. New York, NY: Penguin, 2016.

41 Piper D, ledema R, Gray J, et al. Utilizing experience-based codesign to improve the experience of patients accessing emergency departments in New South Wales public hospitals: an evaluation study. Health Serv Manage Res 2012;25:162-72.

42 Bradwell P, Marr S. Making the most of collaboration: an international survey of public service co-design. London, UK: Demos, 2008.

43 ledema R, Merrick E, Piper D, et al. Codesigning as a discursive practice in emergency health services: the architecture of deliberation. J Appl Behav Sci 2010;46:73-91.

44 Hickey G, Brearley S, Coldham T, et al. Guidance on co-producing a research project. INVOLVE: Southampton, 2018.

45 Staniszewska S, Brett J, Simera I, et al. GRIPP2 reporting checklists: tools to improve reporting of patient and public involvement in research. BMJ 2017;358:j3453.

46 Pawson R, Tilley N. Realistic evaluation. London: Sage, 1997.

47 Rolfe S. Combining theories of change and realist evaluation in practice: lessons from a research on evaluation study. Evaluation 2019;25:294-316. 